\title{
Study Regarding the Use of Sheep Wool in Dendro-Horticultural
}

\author{
Maria $\operatorname{ADI}^{1^{*}}$, Ioan PACURAR ${ }^{2}$ \\ 1) Faculty of Agriculture, University of Agricultural Sciences and Veterinary Medicine Cluj-Napoca, \\ 3-5 Mănăştur St., 400372 Cluj-Napoca \\ *corresponding author, e-mail: ioan.pacurar@usamvcluj.ro
}

Bulletin UASVM series Agriculture 73(1)/2016

Print ISSN 1843-5246; Electronic ISSN 1843-5386

DOI 10.15835/buasvmcn-agr: 12002

\begin{abstract}
In each agricultural exploitation or agribusiness, it is imposed a correct use of fertilizers not just from economical reasons but also in order to protect the environment.

Nitrates Directive (1991) encourages farmers to become more careful with the environment and to try new techniques. By mimimazing the use of fertilizers biodiversity is insured. In many European countries, sheep wool is considered waste. Despite its great features (physical and bio-chemical) sheep wool remains unused, although we can find it in very large quantities. Sheep wool is a $100 \%$ ntural fabric, durable, recyclable and biodegradable and it does not contain any chemical substances or other pollutants. Therefore no toxic substance could infiltrate in surface waters or groundwaters, minimazig water contamination with heavy metals or eutrophication.

The main idea of this study is to develop an innovative strategy by using raw sheep wool as fertilizer. The development of a logistic concept: sheep wool from the farm used on fields. The use of sheep wool is equal with no impacts on the environment, no soil pollution, no water pollution, no soil degradation, which leads to biodiversity preservation.
\end{abstract}

Keywords: soil, sheep wool, fertilization, biodiversity, environment protection.

\section{INTRODUCTION}

A strategy for soil protection made by European Council, alerts that soil degradation is a serious problem which affects fileds all over Europe. That documentstates that techniques used in organic and integrated agriculture or extensive agriculture from mountain areas may maintain and increase the level of chemical substances from soil and also to prevent landslides. Nitrates Directive (1991) encourages farmers to become more careful with the environment and to try new techniques. The main objective of this directive is to reduce water pollution caused or induced of nitrates used in agriculture. The remove of nitrates from soil by their absorption in plant, by levigation or by other processes that are related with the soils natural dynamic, decreases nutritional elements and also produces gradually decline of soil production. Based on this reasons, it is imposed as an objective necessity to aplly mineral and organic fertilizers, due to crop consumption and decreasing of nutrients mobility by natural processes (absorbtion, fixation, imbilization in humic substances) (Borlan et al., 1994).

By minimizing the use of fertilizers, biodiversity is insured. By using sheep wool, a natural and biodegradable soil is not affected. This means that natural fertilizers are great for insure biodiversity of flora and fauna. In many European countries sheep wool is considered waste, although it is a real treasure. It is an unsed material although it is found in large quantities and it has awesome features (physical and bio-chemical). Sheep wool is a $100 \%$ ntural fabric, durable, recyclable and 
biodegradable and it does not contain any chemical substances or other pollutants. Therefore no toxic substance could infiltrate in surface waters or groundwaters. Sheep wool does not affect soil such as synthetic fertilizers, and this leads to biodiversity preservation.

\section{MATERIALS AND METHODS}

For many years, sheep wool was recognized for its potential as raw material in producing fertilizers. Sheep wool has many features, physical and bio-chemical:

It contains up to:

$50 \%$ Carbon

25\% Oxygen

17\% Nitrogen

$6 \%$ Sulphide

(D'arcy, J. B. Sheep management and wool technology. New South Wales University Press. 1972.)

Fertilization strategy is based on a raw material, $100 \%$ biodegradable, sheep wool. In order to be used as nutritional support for vegetation, the wool must be cleaned, washed, expanded, modeled, cut and crumbled (Fig. 2. , Fig. 3., Fig. 4. Fig. 5. ).

Other used materials: treated soil, pearl stone, tomato seeds, blackberry seedling (in vitro), small greenhouses and alveoli.

The experiment was realized in the laboratory, in 03.06.2015, by following the development of two species: blackberry (Rubus fructicosus L.) Chester variety obtained in vitro in an MS culture environment (23.03.2015) and tomato seeds (Solanum lycopersicum), obtained from Agrosem Impex SRL. I have prepared 8 mini cultures (small mini greenhouses), each one containing 42 holes or alveoli.

Work method for Blackberry (Rubus fructicosus $L$.):

- 4 trays with 42 holes

- 1 tray contains washed and crumbled wool with treated soil (Florino) 1:1

- 1 tray with washed wool

- 1 tray with unwashed wool

-1 tray with pearl stones (witness sample)

Work method for tomatos (Solanum lycopersicum):

- 4 trays with 42 holes

- 1 tray contains washed and crumbled wool with treated soil (Florino) 1:1

- 1 tray with washed wool

- 1 tray with unwashed wool

-1 tray with pearl stones (witness sample)

The temperature in june in 2015:

Maximum : $17^{\circ}-31^{\circ} \mathrm{C}$

Minimum : $8^{\circ}-15^{\circ} \mathrm{C}$

\section{RESULTS AND DISCUSSIONS}

This sample were made with the purpose of establish if sheep wool can be used as substrate in dendro-horticultural crops.

At experimental crops, the greatest development among plants was obtain in the trays in which washed wool was used and also in the ones with mixture of washed wool and treated soil.

The plants were monitored daily. In those two substrates, tomato seeds germination started after 3 days, and blackberry seedlings had significant roots after 21 days (compared with the witness sample) (Fig.6.).

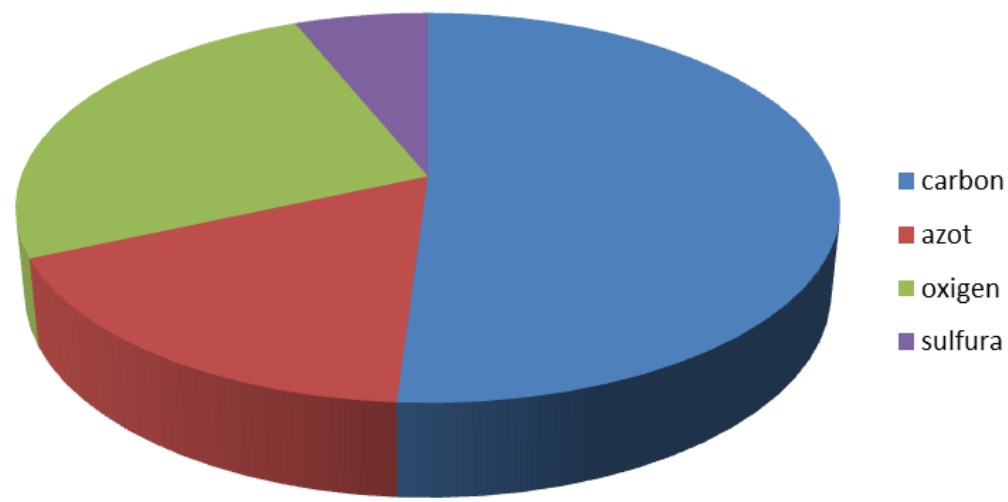

Fig. 1 


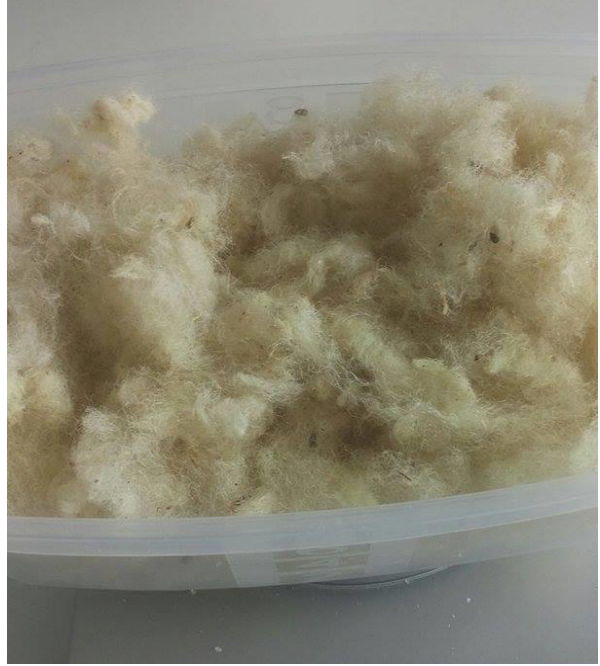

Fig. 2. Washed and expanded wool



Fig.4. Blackberry seedling

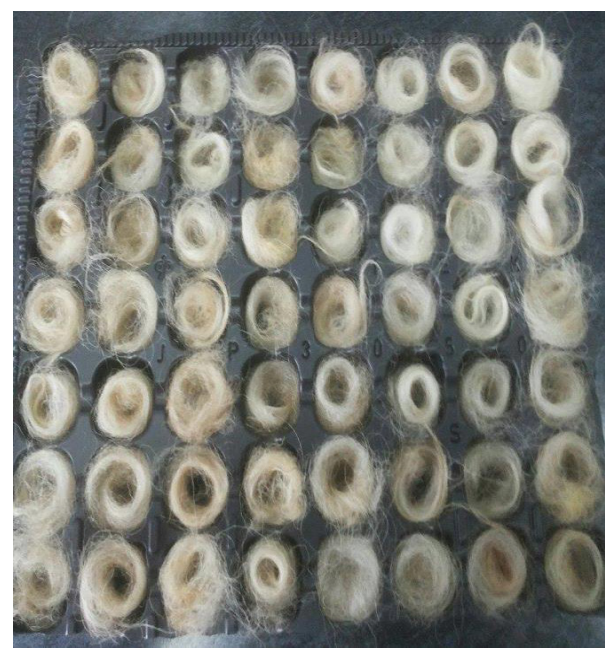

Fig. 3. Wool in alveoli

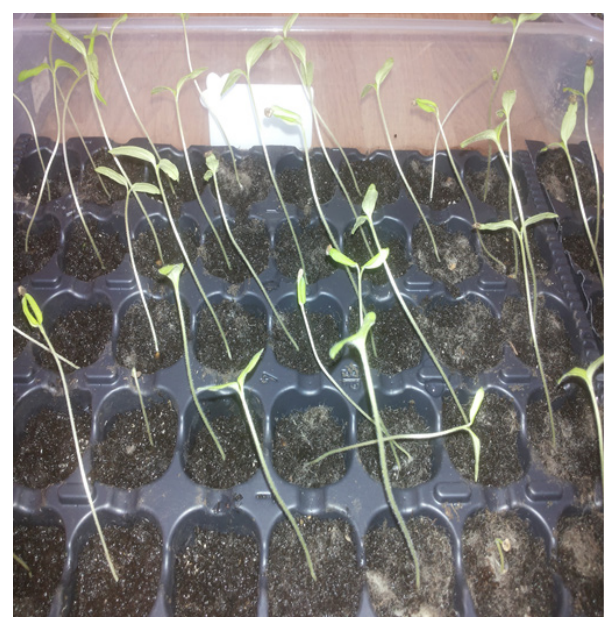

Fig.5. Tomatos

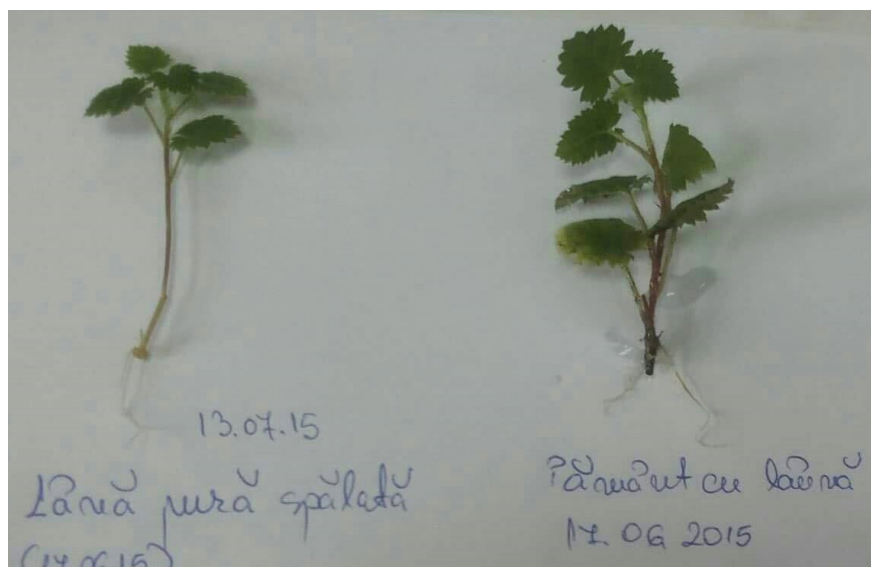

Fig. 6. Blackberry root development 
Regarding the plant development from the trays in which wool was used unwashed we can notice that the root system did not developed due to an acid environment.

Due to economical and also environmental protection policies, sheep wool can be used as a substrate in dendro-horticultural crops. Sheep wool is a $100 \%$ ntural fabric, durable, recyclable and biodegradable and it does not contain any chemical substances or other pollutants. Therefore no toxic substance could infiltrate in surface waters or groundwaters. Sheep wool does not affect soil such as synthetic fertilizers, and this leads to biodiversity preservation. Wool fibres expand at water contact, ventilating the soil, a positive aspect for root development. Releasing nutrients from sheep wool is effective, fact that minimizes the efforts of refertilizing during season.

Also, sheep wool, has an amazing absorbing capacity and also maintains water, and this prevents soil drying, which leads to minimize erosion.

\section{CONCLUSION}

Farmers are encouraged to become more careful with the environment and to try new techniques.

The main objective of this study is to develop an innovative strategy of fertilization by using sheep wool. The development of a logistic concept: farm sheep wool used on the fields.

In many European countries, sheep wool is considered waste. Despite its great features (physical and bio-chemical) sheep wool remains unused, although we can find it in very large quantities. Sheep wool is a $100 \%$ ntural fabric, durable, recyclable and biodegradable and it does not contain any chemical substances or other pollutants.

In order for the wool to be used as nutritional support the wool must be cleaned, washed, expanded, modeled, cut and crumbled.
The experiment was realized in the laboratory, in 03.06.2015, by following the development of two species: blackberry (Rubus fructicosus L.) Chester variety obtained in vitro in an MS culture environment (23.03.2015) and tomato seeds (Solanum lycopersicum), obtained from Agrosem Impex SRL. I have prepared 8 trays (small mini greenhouses), each one containing 42 holes or alveoli.

At experimental crops, the greatest development among plants was obtained in the trays with washed wool was and in the ones with mixture of washed wool and treated soil.

Regarding the plant development from the trays in which wool was used unwashed we can notice that the root system did not developed due to an acid environment.

Due to economical and also environmental protection policies, sheep wool can be used as a substrate in dendro-horticultural crops.

\section{REFERENCES}

1. D'arcy JB (1972). Sheep management and wool technology. New South Wales University Press.

2. Spanish Ministry of Agriculture (MAGRAMA). Resultados de la encuesta ganadera para ganado Ovino-Caprino. Informes 2011.

3. http://www.oviespana.com/informacion-de-ovino/ cotizaciones-de- mercado/seccion/Lana

4. Velthof G.L., J.P. Lesschen, J. Webb, S. Pietrzak, Z. Miatkowski, J. Kros, M. Pinto, \& O. Oenema. The impact of the Nitrates Directive on gaseous $\mathrm{N}$ emissions. Effects of measures in nitrates action programme on gaseous $\mathrm{N}$ emissions.

5. Contract ENV.B.1/ETU/2010/0009

6. AGP-Agriculture and soil biodiversity. FAO. http://www. fao.org/agriculture/crops/thematic-sitemap/theme/ spi/soil-biodiversity/agriculture-and-soil-biodiversity/ en/

7. http://www.icpa.ro/Coduri/Planuri_de_fertilizare.pdf

8. http://www.eutopiamall.com/images/MD/1168700/Mo nitorizarea+fertilitatii+soluluii.pdf 